\title{
Quantum Monte Carlo Simulations and High-Field Magnetization Studies of Antiferromagnetic Interactions in a Giant Hetero-Spin Ring
}

DOI:

10.1002/anie.201709650

\section{Document Version}

Accepted author manuscript

Link to publication record in Manchester Research Explorer

Citation for published version (APA):

Qin, L., Singleton, J., Chen, W-P., Nojiri, H., Engelhardt, L., Winpenny, R., \& Zheng, Y-Z. (2017). Quantum Monte Carlo Simulations and High-Field Magnetization Studies of Antiferromagnetic Interactions in a Giant Hetero-Spin Ring. Angewandte Chemie - International Edition. https://doi.org/10.1002/anie.201709650

Published in:

Angewandte Chemie - International Edition

\section{Citing this paper}

Please note that where the full-text provided on Manchester Research Explorer is the Author Accepted Manuscript or Proof version this may differ from the final Published version. If citing, it is advised that you check and use the publisher's definitive version.

\section{General rights}

Copyright and moral rights for the publications made accessible in the Research Explorer are retained by the authors and/or other copyright owners and it is a condition of accessing publications that users recognise and abide by the legal requirements associated with these rights.

\section{Takedown policy}

If you believe that this document breaches copyright please refer to the University of Manchester's Takedown Procedures [http://man.ac.uk/04Y6Bo] or contact uml.scholarlycommunications@manchester.ac.uk providing relevant details, so we can investigate your claim.

\section{OPEN ACCESS}




\title{
Quantum Monte Carlo Simulations and High-Field Magnetization Studies of Antiferromagnetic Interactions in a Giant Hetero-Spin Ring**
}

\author{
Lei Qin, ${ }^{1}$ Jared Singleton, ${ }^{2}$ Wei-Peng Chen, ${ }^{1}$ Hiroyuki Nojiri, ${ }^{3}$ Larry Engelhardt, ${ }^{2, *}$ Richard E. P. \\ Winpenny ${ }^{4, *}$ and Yan-Zhen Zheng ${ }^{1, *}$
}

\begin{abstract}
We report chromium-lanthanide heterometallic wheel complexes $\left\{\mathrm{Cr}_{8} L n_{8}\right\}$ (Ln $=\mathrm{Gd}$, Dy and $\mathrm{Y}$ ) with alternating metal centers. Quantum Monte Carlo simulations reveal antiferromagnetic exchange-coupling constants with an average of $2.1 \mathrm{~K}$ within the $\left\{\mathrm{Cr}_{8} \mathrm{Gd}_{8}\right\}$ wheel, which leads to a large ground spin state $\left(S_{T}=16\right)$ that is confirmed by magnetization studies up to 20 Tesla. The $\left\{\mathrm{Cr}_{8} D y_{8}\right\}$ wheel is a single-molecule magnet.
\end{abstract}

Understanding magnetic interactions is at the heart of molecular magnetism, a research field that leads to the exciting discovery of single-molecule magnets, ${ }^{1,2}$ single-chain magnets, ${ }^{3}$ molecular magnetic refrigerants, ${ }^{4}$ spin-based qubits ${ }^{5}$ and single-molecule toroics. ${ }^{6}$ Cyclic polymetallic compounds are of particular interest as models of infinite 1D chains, but with finite size, which may provide deeper insight to the magnetic interactions and excitations. Particularly relevant to the work reported here are mixed metal rings incorporating both $3 \mathrm{~d}$ and $4 \mathrm{f}$ metal ions are less. Examples include $\left\{\mathrm{Mn}_{4}{ }_{4} \mathrm{Ln}_{4}\right\},{ }^{7 \mathrm{a}} \quad\left\{\mathrm{Mn}^{\mathrm{II \prime}}{ }_{8} \mathrm{Ln}_{8}\right\},{ }^{7 \mathrm{~b}} \quad\left\{\mathrm{Fe}^{\mathrm{II \prime}}{ }_{10} \mathrm{Ln}_{10}\right\},{ }^{8}$ $\left.\left\{\mathrm{Ni}^{11}{ }_{12} \mathrm{Ln}_{36}\right\},{ }^{9 \mathrm{a}} \quad \mathrm{Cu}^{\prime \prime}{ }_{36} \mathrm{Ln}_{24}\right\}^{9 \mathrm{~b}}$ and $\left\{\mathrm{Co}_{16}{ }_{16} \mathrm{Ln}_{24}\right\}{ }^{9 \mathrm{c}} \quad \mathrm{Cr}(\mathrm{III})$-based heterometallic $3 \mathrm{~d}-4 \mathrm{f}$ rings include $\left\{\mathrm{Cr}^{\prime \prime \prime}{ }_{3} \mathrm{Ln}_{3}\right\}$ and $\left\{\mathrm{Cr}_{4}^{\prime \prime \prime}{ }_{4} \mathrm{Ln}_{4}\right\}$ reported by the Powell group, ${ }^{10}$ and $\left\{\mathrm{Cr}^{\prime \prime \prime}{ }_{6} \mathrm{Ln}_{2}\right\}$ and $\left\{\mathrm{Cr}^{\prime \prime \prime \prime}{ }_{12} \mathrm{Ln}_{4}\right\}$ cages reported by McRobbie et al. ${ }^{11}$

Here we report the largest $\mathrm{Cr}(\mathrm{III})-\mathrm{Ln}$ (III) heterometallic wheel, $\left[\mathrm{Cr}_{8} \mathrm{Ln}_{8}\right.$ (mdea) $\left.{ }_{16}\left(\mathrm{CH}_{3} \mathrm{COO}\right)_{8}\left(\mathrm{NO}_{3}\right)_{8}\right] \cdot x \mathrm{CH}_{3} \mathrm{CN}$ (1) $\left(\mathrm{mdeaH}_{2}\right.$ $=N$-methyldiethanolamine, $x=3,6$ and 3 for 1-Gd, 1-Dy and 1$\mathrm{Y}$, respectively) with sixteen alternating $\mathrm{Cr}$ and $\mathrm{Ln}$ metal centers. High-Field Magnetization and quantum Monte Carlo (QMC) simulation ${ }^{12-14}$ studies indicate that $\mathbf{1 - G d}$ displays a ferrimagnetic ground state $\left(S_{\mathrm{T}}=16\right)$ due to the antiferromagnetically-coupled

[1] Dr. L. Qin, W.-P. Chen and Prof. Dr. Y.-Z. Zheng

Frontier Institute of Science and Technology (FIST),

Xi'an Jiaotong University,

Xi'an 710054, China

Fax: (+) 86-29-83395131

Email: zheng.yanzhen@xjtu.edu.cn

Website: http://gr.xjtu.edu.cn/web/zheng.yanzhen/home

[2] J Singleton and Prof. Dr. L. Engelhardt

Department of Physics and Astronomy, Francis Marion University, Florence, SC 29502, USA

Fax: (843)-661-1452

Email: lengelhardt@fmarion.edu

[3] Prof. Dr. H. Nojiri

Institute of Materials Research (IMR), Tohoku University, Katahira, Sendai 980-8577, Japan

[4] Prof. Dr. R. E. P. Winpenny

Department of Chemistry and Photon Science Institute,

The University of Manchester

Manchester, M13 9PL, UK

Email: richard.winpenny@manchester.ac.uk

[** Supporting information for this article is given via a link at the end of the document. neighbouring spins. The 1-Dy complex shows slow magnetic relaxation and non-tunneling zero-field magnetic hysteresis loop at low temperatures, and together with the absence of frequency-dependent ac susceptibility of a diluted sample, suggests an unusual molecule-originated magnet-type behaviour in large $3 \mathrm{~d}-4 \mathrm{f}$ mixed metal clusters.

All of the three complexes are isostructural and crystalize in the orthorhombic space group $F_{d d d}$ (Figure 1 and Table S1). Hence, the structure of $\mathbf{1 - G d}$ is described as representative. In 1-Gd, the eight $\mathrm{Cr}(\mathrm{III})$ and eight $\mathrm{Gd}(\mathrm{III})$ ions are arranged alternately to form a ring with $\mathrm{C}_{2}$ symmetry. Each $\mathrm{Cr}(\mathrm{III})$ atom is six-coordinate, bound to O-donors provided by three 3.212 (in Harris notation ${ }^{15}$ ) mdea $^{2-}$ ligand (Figure S1) and one 2.11 acetate ligand; the acetate is generated in situ from acetylacetone or acetonitrile under solvothermal conditions. ${ }^{16}$ For each $\mathrm{Gd}(\mathrm{III})$ site, the coordination is similar to $\mathrm{Cr}$ (III) sites except for an additional 1.11 nitrate anion, affording the eightcoordinate environment. The $\mathrm{Cr}-\mathrm{O}$ distances are from 1.96 to $2.00 \AA$ while the $\mathrm{Gd}-\mathrm{O}$ distances are from 2.32 to $2.52 \AA$ (Table $\mathrm{S} 2)$. The $\mathrm{Cr}-\mathrm{N}$ and $\mathrm{Gd}-\mathrm{N}$ distances are in the range from 2.14 to $2.15 \AA$ and from 2.65 to $2.94 \AA$, respectively. The $\mathrm{Cr} \cdots \mathrm{Gd}$ distances alternate between $3.48 \AA$ and $3.37 \AA$. In the single crystal the molecules pack in an $A B A B$ fashion (Figure $S 2$ ).

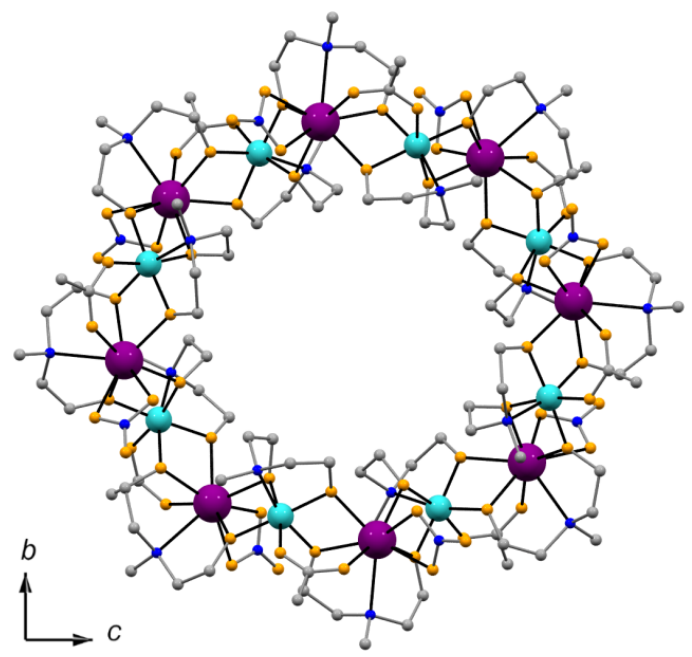

Figure 1. a) The molecular structure of complex 1-Gd. Color codes: $\mathrm{Cr}$, aqua; $\mathrm{Gd}$, violet; $\mathrm{C}$, gray; $\mathrm{N}$, blue; $\mathrm{O}$, little orange. The hydrogen atoms were omitted for clarity.

Dc magnetic susceptibilities of poly-crystalline samples of 1-Gd and 1-Dy and 1-Y were measured from 0.5 to $300 \mathrm{~K}$ (for 1-Y data were measured 2.0 to 300 , see supporting information) (Figure $2 \mathrm{a}$ and $\mathrm{S} 3$ ). At room temperature, the $X^{T}$ products (in unit of $\mathrm{cm}^{3} \mathrm{~mol}^{-1} \mathrm{~K}$ ) of three samples are all in good agreement with the expected values for eight non-interacting $\mathrm{Cr}(\mathrm{III})$ and 
eight non-interacting $\operatorname{Ln}(\mathrm{III})$ ions. Upon cooling, 1-Gd and 1-Dy show similar behaviors where the $X T$ product decreases slowly down to a minimum at ca. $6 \mathrm{~K}$ before abruptly increasing. For 1 $Y$, the $X^{T}$ product is roughly constant until $10 \mathrm{~K}$, followed by a slow increase to $2 \mathrm{~K}$. For 1-Gd, 1-Dy and 1-Y, the Curie-Weiss fitting for the $X^{-1}$ vs. $T$ plots affords Curie constants $(C)$ of 78.9 , 132.8 and $14.8 \mathrm{~cm}^{3} \mathrm{~mol}^{-1} \mathrm{~K}$ and Weiss constant $(\theta)$ of -8.53 , -13.41 and $2.19 \mathrm{~K}$ (Figure S4), respectively. These behaviors indicate dominant antiferromagnetic interactions in 1-Gd and 1Dy and weak ferromagnetic interaction in 1-Y.

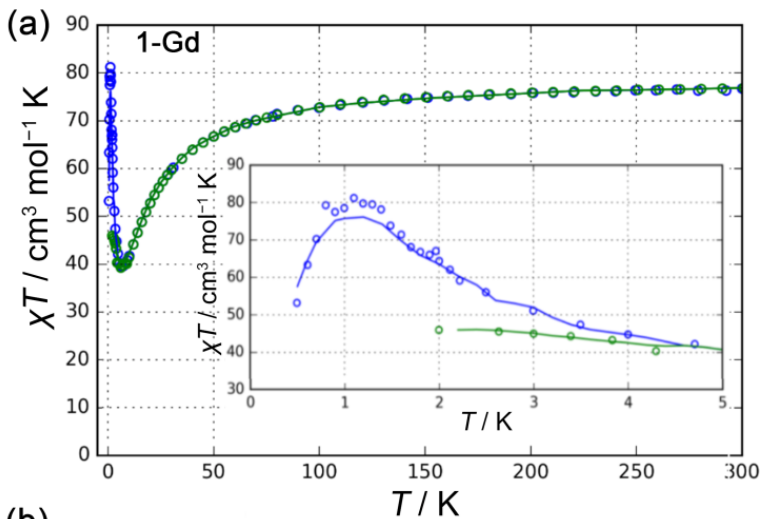

(b)

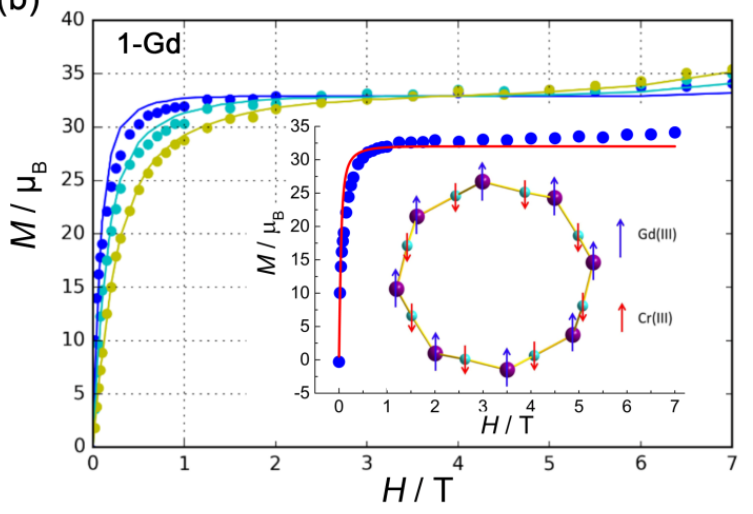

Figure 2. (a) Temperature-dependent dc magnetic susceptibility plots (dots) and QMC calculations (lines, see text below) for 1-Gd under the field of 1000 (blue) and $5000 \mathrm{Oe}$ (green). Insert: amplifying the $T<5 \mathrm{~K}$ data. (b) Fielddependent magnetization data (dots) and QMC calculations (lines) from 0.5 to $1.5 \mathrm{~K}$ (color codes: $0.5 \mathrm{~K}$, blue; $1.0 \mathrm{~K}$, cyan; $1.5 \mathrm{~K}$, yellow) for $1-\mathrm{Gd}$. Insert: the magnetization data at $0.5 \mathrm{~K}$ together with the Brillouin function plot (red line) of $S=16$ for $g=2.0$ and the proposed spin arrangement diagram for the ground state.

For 1-Gd, $M(H)$ measurements show that magnetisation saturates before $1 \mathrm{~T}$ and remains constant to $5 \mathrm{~T}$ before increasing again (0.5-1.5 K, Figure $2 \mathrm{~b})$. The magnetization saturates more slowly at higher temperatures (Figure S5). At 0.5 $\mathrm{K}$, the magnetization values of the flat region are all around 32 34 $\mu_{\mathrm{B}}$ which suggest an $S=16$ ground state. In addition, the Brillouin function for $S=16(g=2.0)$ at $0.5 \mathrm{~K}$ agrees well with the experimental data, especially when the field is lower than $4 \mathrm{~T}$ (insert in Figure 2b), suggesting a well isolated ferrimagnetic spin ground state. The non-zero slope of $M$ vs. $H$ at higher fields should be originated from the partial population of the low-lying excited states, which is consistent with the trend seen here that this slope decreases as the temperature is lowered from 1.5 to $0.5 \mathrm{~K}$. A possible schematic diagram for the spin arrangements (insert in Figure $2 \mathrm{~b}$ ) was proposed for the ferrimagnetic state.

For 1-Dy, the field-dependent magnetization was also measured from $0.5 \mathrm{~K}$ to $4 \mathrm{~K}$ (Figure S6). The magnetizations at $0.5 \mathrm{~K}$ and $7 \mathrm{~T}$ are $52.5 \mu_{\mathrm{B}}$ without saturations. This indicates the presence of significant magnetic anisotropy and/or the population of low-lying excited states in this complex. For 1-Y, the magnetization plots from $2 \mathrm{~K}$ to $4 \mathrm{~K}$ were measured (Figure S7), the value at $2 \mathrm{~K}$ and $7 \mathrm{~T}$ is $24.0 \mu_{\mathrm{B}}$, in accordance with the saturation value for eight $\mathrm{Cr}$ (III) ions. The plot at $2 \mathrm{~K}$ is a similar to the Brillouin function for eight non-interacting $\mathrm{Cr}$ (III) ions but $M$ increases slightly more rapidly which confirms the weak ferromagnetic interaction between the $\mathrm{Cr}$ (III) ions.

Although the wheel-like geometry provides a relatively simple magnetic interaction pathway, the Hilbert space for 1-Gd is still too large to perform matrix diagonalization $\left(\sim 10^{12}\right)$. Herein, we simulated the magnetic data using a quantum Monte Carlo method with the stochastic series expansion implementation from Algorithms and Libraries for Physics Simulations (ALPS) for 1-Gd (Figures 2 and 3). ${ }^{12-14}$ Because the $\mathrm{Cr} \cdots \mathrm{Gd}$ distances are not all equal and can be divided into two subgroups (3.37 and $3.48 \AA$ ), a two-J model based on the following Hamiltonian was used:

$$
\begin{aligned}
\widehat{H}=J_{1} \sum_{i=1}^{8} \hat{\vec{s}}_{\mathrm{Cr}_{i}} \cdot \hat{\vec{s}}_{\mathrm{Gd}_{i}}+J_{2} \sum_{i=1}^{7} \hat{\vec{s}}_{\mathrm{Cr}_{i+1}} \cdot \hat{\vec{s}}_{\mathrm{Gd}_{i}}+J_{2} \hat{\vec{s}}_{\mathrm{Cr}_{1}} \cdot \hat{\vec{s}}_{\mathrm{Gd}_{8}}-\mu_{B} H \sum_{i=1}^{8} g_{\mathrm{Cr}} \hat{\vec{s}}_{\mathrm{Cr}_{i z}} \\
-\mu_{B} H \sum_{i=1}^{8} g_{\mathrm{Gd}} \hat{\vec{s}}_{\mathrm{Gd}_{i z}}+\sum_{i=1}^{8} D_{\mathrm{Cr} \hat{\vec{s}}_{\mathrm{Cr}_{i z}}^{2}}
\end{aligned}
$$

This model uses the sign convention where $J>0$ represents an antiferromagnetic interaction, but also included a single zerofield splitting term, $D_{\mathrm{Cr}}$, for each $\mathrm{Cr}(\mathrm{III})$ site. The symbol $\hat{\vec{s}}_{i}$ denotes the spin vector operator for site $i$ and $g$ is the Landé factor. All $J$ values will be reported in units of Kelvin $(K)$, meaning that $J / \mathrm{k}_{B}$ has the value reported, given in units of $K$. The system consists of eight $\mathrm{Cr}(\mathrm{III})$ ions and eight $\mathrm{Gd}(\mathrm{III})$ ions, where each $\mathrm{Cr}(\mathrm{III})$ ion has $s=3 / 2$, and each $\mathrm{Gd}(\mathrm{III})$ ion has $s=$ $7 / 2$. Hence, the two- $J$ alternate around the ring as $\left(J_{1}, J_{2}, J_{1}, J_{2}\right.$, etc., Figure S8). The plots in Figure 2 show experiment and theory for the two- $J$ model, using the parameters which gave the best fit: $J_{1}=0.74 \mathrm{~K}, J_{2}=3.46 \mathrm{~K}, D_{\mathrm{Cr}}=0.175 \mathrm{~K}, g_{\mathrm{Cr}}=1.98$ and $g_{\mathrm{Gd}}=2.03$. The $J$ values determined the shape of the curves for $T>2 \mathrm{~K}$, and the curvature of the plot for $T<2 \mathrm{~K}$ is determined by the value of $D_{\mathrm{cr}}$. The effect of the $J_{2} / J_{1}$ ratio on the theoretical data was also shown in Figure S9, where the susceptibility plots were displayed using different $J_{2} / J_{1}$ ratios with a fixed value of the average, $\left(J_{1}+J_{2}\right) / 2=2.1 \mathrm{~K}$. A ratio of $J_{2} / J_{1}=1$, which corresponds to the single- $J$ model, does not provided a deep enough "dip" to match the experimental data around $T=5$ to 10 $\mathrm{K}$. As the ratio $J_{2} / J_{1}$ is increased, this dip becomes deeper, and a ratio of $J_{2} / J_{1}>4$ is needed in order to fit the data in this temperature range.

To confirm this Monte Carlo calculation, we measured the high-field magnetization using a pulsed magnetic field up to about $20 \mathrm{~T}$ (a full cycle from 0 to $20 \mathrm{~T}$ and then go back to $0 \mathrm{~T}$ ) 
at $0.4 \mathrm{~K}$ (Figure 3). When the field is larger than $7 \mathrm{~T}$, the magnetization continues to increase until to the saturation value around 18 20 T. The near linear increase from 7 to $16 \mathrm{~T}$ shows the dominant antiferromagnetic interactions in 1-Gd system. There is some small hysteresis that can be seen in the experimental data between the up and down cycle, particularly in the range $0<H<2 \mathrm{~T}$ which originates from the competition between the thermal relaxation and the fast change of the magnetic field. ${ }^{17}$ In this range, the upper curve matches the theory data very well. There are some deviations that are probably due to some anisotropy in the system. For example, the theory predicts small "wiggles" in $M$ vs. $H$ between 8 and 16 $\mathrm{T}$ where the experimental data are smooth. The wiggles in the theory data are due to ground-state level crossings, which could be smoothed out in the experimental data if these level crossings are replaced by avoided crossings, caused by the slight anisotropy.

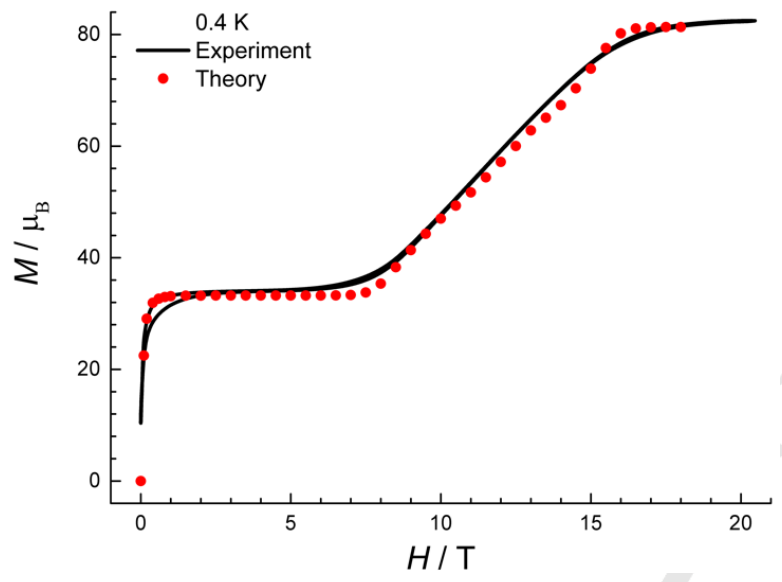

Figure 3. Field-dependent magnetization data (black lines) and QMC calculation (red dots) at $0.4 \mathrm{~K}$ for $1-\mathrm{Gd}$

Alternating-current (ac) susceptibility measurements were also carried out on thee three samples. For 1-Gd and 1-Y, no slow magnetic relaxation behaviors were observed (Figure S10). Compound 1-Dy shows in-phase $\left(X^{\prime}\right)$ and out-of-phase $\left(X^{\prime \prime}\right)$ signals that are temperature- and frequency-dependent under zero dc field (Figures S11 and S12). The Cole-Cole plots of $X^{\prime}$ versus $X^{\prime \prime}$ from 1.9 to $2.7 \mathrm{~K}$ suggest a single relaxation process is operational, which can be fitted using a generalized Debye model with $\alpha$ values ranging from 0.04 to 0.13 . Evaluated from the relaxation time $\tau$ (Table S3), the linear plot of $\ln (\tau$ ) versus $1 / T$ was revealed, implying an Orbach process is dominant over the measured temperature and frequency span. The fitting of the Arrhenius law $T=T_{0} \exp \left(U_{\text {eff } /} k_{\mathrm{B}} T\right)$ affords the $U_{\text {eff }}$ of $19.0 \mathrm{~K}$ with $T_{0}$ $=3.5 \times 10^{-8} \mathrm{~s}$, which is reasonable compared to other SMMs. ${ }^{2}$

We measured the magnetic hysteresis plots of 1-Dy which shows an open magnetic hysteresis loop at $0.5 \mathrm{~K}$ (Figure 4). The coercive field of the open hysteresis is about 1400 Oe with average sweep field rate of $6 \mathrm{Oe} \mathrm{s}^{-1}$. This we ascribe to the $\mathrm{Cr}$ (III)-Dy(III) interactions which effectively suppress the zerofield QTMs. This phenomenon was also observed in some other $\mathrm{Cr}$ (III)-Dy(III) systems. ${ }^{18}$ Further ac susceptibility measurements were made on a sample of single Dy"l ions doped into 1-Y, namely $1-Y_{0.954} D_{y_{0.046}}$ (see supporting information and Table S4); these show no slow relaxation of magnetisation (Figure S13). Therefore, we can conclude that the slow magnetic relaxation behavior of 1-Dy is originated from the molecule based on $\mathrm{Cr}$ (III)-Dy(III) exchange-couplings rather than the single ion origin of Dy(III) ions.

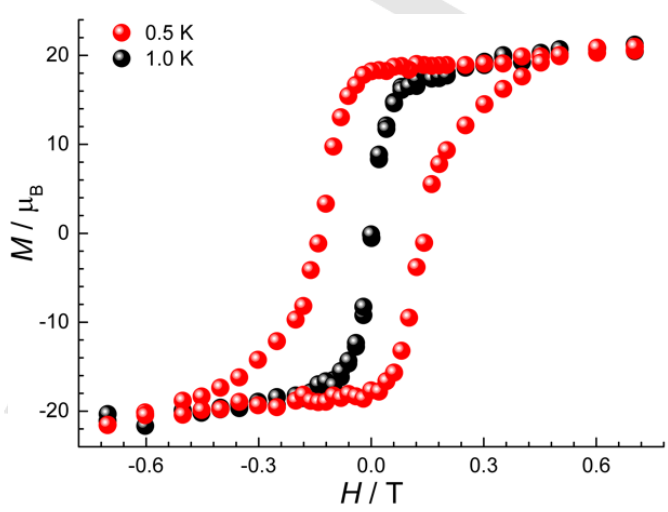

Figure 4. Magnetic hysteresis plots at 0.5 and $1.0 \mathrm{~K}$ for 1-Dy with average sweep field of $6 \mathrm{Oe} \mathrm{s}^{-1}$

\section{Acknowledgements}

This work was supported by NSFC (21473129, 21620102002, and 21773130), "National Young 1000-Plan" program, the Cyrus Chung Ying Tang Foundation and Wuhan National HighMagnetic Field Center (2015KF06).

Keywords: cyclic coordination clusters $\cdot \mathrm{Cr}-\mathrm{Ln} \cdot$ Quantum Monte Carlo• exchange-coupling $\bullet$ single-molecule magnets

[1] a) A. Bencini, C. Benelli, A. Caneschi, R. L. Carlin, A. Dei, D. Gatteschi, J. Am. Chem. Soc. 1985, 107, 8128; b) R. Sessoli, D. Gatteschi, A. Caneschi, M. A. Novak, Nature 1993, 365, 141.

[2] a) M. Manoli, R. Inglis, M. J. Manos, V. Nastopoulos, W. Wernsdorfer, E. K. Brechin, A. J. Tasiopoulos, Angew. Chem. Int. Ed. 2011, 50, 4441; Angew. Chem. 2011, 123, 4533; b) D. N. Woodruff, R. E. P. Winpenny, R. A. Layfield, Chem. Rev. 2013, 113, 5110; c) K. Liu, W. Shi, P. Cheng, Coord. Chem. Rev. 2015, 289-290, 74.

[3] a) A. Caneschi, D. Gatteschi, N. Lalioti, C. Sangregorio, R. Sessoli, G. Venturi, A. Vindigni, A. Rettori, M. G. Pini, M. A. Novak, Angew. Chem. Int. Ed. 2001, 40, 1760; Angew. Chem. 2001, 113, 1810; b) R. Clérac, H. Miyasaka, M. Yamashita, C. Coulon, J. Am. Chem. Soc. 2002, 124, 12837 ; c) C. Coulon, H. Miyasaka, R. Clérac, Struct. Bonding, Springer, Berlin, 2006, 122, 163.

[4] a) M. Evangelisti, E. K. Brechin, Dalton Trans. 2010, 39, 4672; b) R. Sessoli, Angew. Chem. Int. Ed. 2012, 51, 43; Angew. Chem. 2012, 124 , 43; c) Y. Z. Zheng, G. J. Zhou, Z. Zheng, R. E. P. Winpenny, Chem. Soc. Rev. 2014, 43, 1462.

[5] a) E. J. L. Mclnnes, G. A. Timco, G. F. S. Whitehead, R. E. P. Winpenny, Angew. Chem. Int. Ed. 2015, 54, 14244; Angew. Chem. 2015, 127, 14450; b) A. Ardavan, A. Bowen, A. Fernandez, A. Fielding, D. Kaminski, F. Moro, C. A. Muryn, M. Wise, A. Ruggi, E. J. L. Mclnnes, K. Severin, G. A. Timco, C. Timmel, F. Tuna, G. F. S. Whitehead and R. E. P. Winpenny, npj Quantum Information, 2015, 1, 15012; c) A. Fernandez, J. Ferrando-Soria, E. M. Pineda, F. Tuna, I. J. Vitorica- 
Yrezabal, C. Knappke, J. Ujma, C. A. Muryn, G. A. Timco, P. E. Barran, A. Ardavan and R. E. P. Winpenny, Nat. Commun. 2016, 7, 10240; d) J. Ferrando-Soria, E. Moreno Pineda, A. Chiesa, A. Fernandez, S. A. Magee, S. Carretta, P.Santini, I. J. Vitorica-Yrezabal, F. Tuna, G. A. Timco, E. J. L. McInnes and R. E. P. Winpenny, Nat. Commun. 2016, 7, 11377; e) E. Garlatti, T. Guidi, S. Ansbro, P. Santini, G. Amoretti, J. Ollivier, H. Mutka, G. Timco, I. J. Vitorica-Yrzebal, G. F. S. Whitehead, R. E. P. Winpenny and S. Carretta, Nat. Commun. 2017, 8, 14543.

[6] a) I. J. Hewitt, J.-K. Tang, N. T. Madhu, C. E. Anson, Y. Lan, J. Luzon, M. Etienne, R. Sessoli, A. K. Powell, Angew. Chem. Int. Ed. 2010, 49 6352; Angew. Chem. 2010, 122, 6496; b) L. Ungur, S.-Y. Lin, J.-K. Tang, L. F. Chibotaru, Chem. Soc. Rev. 2014, 43, 6894.

[7] a) M.-Y. Li, Y. Lan, A. M. Ako, W. Wernsdorfer, C. E. Anson, G. Buth, A. K. Powell, Z.-M. Wang, S. Gao, Inorg. Chem. 2010, 49, 11587; b) K. R. Vignesh, S. K. Langley, B. Moubaraki, K. S. Murray, G. Rajaraman, Chem. Eur. J. 2015, 21, 16364.

[8] A. Baniodeh, C. E. Anson, A. K. Powell. Chem. Sci. 2013, 4, 4354.

[9] a) J. B. Peng, Q. C. Zhang, X. J. Kong, Y. P. Ren, L. S. Long, R. B. Huang, L. S. Zheng, Z. Zheng, Angew. Chem. Int. Ed. 2011, 50, 10649; Angew. Chem. 2011, 123, 10837; b) J.-D. Leng, J.-L. Liu, M.-L. Tong, Chem. Commun. 2012, 48, 5286; c) Z.-M. Zhang, L.-Y. Pan, W.-Q. Lin, J.-D. Leng, F.-S. Guo, Y.-C. Chen, J.-L. Liu, M.-L. Tong, Chem. Commun. 2013, 49, 8081.

[10] a) J. Rinck, G. Novitchi, W. Van den Heuvel, L. Ungur, Y. Lan, W. Wernsdorfer, C. E. Anson, L. F. Chibotaru, A. K. Powell, Angew. Chem. Int. Ed. 2010, 49, 7583; Angew. Chem. 2010, 122, 8190; b) J. Rinck, Y. Lan, C. E. Anson, A. K. Powell, Inorg. Chem. 2015, 54, 3107.

[11] A. McRobbie, A. R. Sarwar, S. Yeninas, H. Nowell, M. L. Baker, D. Allan, M. Luban, C. A. Muryn, R. G. Pritchard, R. Prozorov, G. A. Timco, F. Tuna, G. F. S. Whitehead, R. E. P. Winpenny, Chem. Commun. 2011, 47, 6251.

[12] L. Engelhardt, C. Schröder in Molecular Cluster Magnets (Ed.: R. E. P. Winpenny), World Scientific Publishers, Singapore, 2011, pp. 241-291.

[13] a) A. M. Todea, A. Merca, H. Bögge, J. van Slageren, M. Dressel, L. Engelhardt, M. Luban, T. Glaser, M. Henry, A. Müller, Angew. Chem. Int. Ed. 2007, 46, 6106; Angew. Chem. 2007, 119, 6218; b) L. P. Engelhardt C. A. Muryn, R. G. Pritchard, G. A. Timco, F. Tuna, R. E. P. Winpenny, Angew. Chem. Int. Ed. 2008, 47, 924; Angew. Chem. 2008, 120, 938; c) X. Fang, L. Hansen, F. Haso, P. Yin, A. Pandey, L. Engelhardt, I. Slowing, T. Li, T. Liu, M. Luban, D. C. Johnston, Angew. Chem. Int. Ed. 2013, 52, 10500; Angew. Chem. 2013, 125, 10694.

[14] a) B. Bauer, L. D. Carr, H. G. Evertz, A. Feiguin, J. Freire, S. Fuchs, L. Gamper, J. Gukelberger, E. Gull, S. Guertler, A. Hehn, R. Igarashi, S. V. Isakov, D. Koop, P. N. Ma, P. Mates, H. Matsuo, O. Parcollet, G. Pawlowski, J. D. Picon, L. Pollet, E. Santos, V. W. Scarola, U. Schollwoeck, C. Silva, B. Surer, S. Todo, S. Trebst, M. Troyer, M. L. Wall, P. Werner, S. Wessel, J. Stat. Mech.: Theory Exp. 2011, P05001; b) A. F. Albuquerque, F. Alet, P. Corboz, P. Dayal, A. Feiguin, S. Fuchs, L. Gamper, E. Gull, S. Guertler, A. Honecker, R. Igarashi, M. Koerner, A. Kozhevnikov, A. Laeuchli, S. R. Manmana, M. Matsumoto, I. P. McCulloch, F. Michel, R. M. Noack, G. Pawlowski, L. Pollet, T. Pruschke, U. Schollwoeck, S. Todo, S. Trebst, T. Troyer, P. Werner, S. Wessel, J. Magn. Magn. Mater. 2007, 310, 1187.

[15] R. A. Coxall, S. G. Harris, D. K. Henderson, S. Parsons, P. A. Tasker, R. E. P. Winpenny, J. Chem. Soc., Dalton Trans. 2000, 2349.

[16] a) R. Kuhlman, G. L. Schimek, J. W. Kolis, Inorg. Chem. 1999, 38, 194; b) G. Thiele, B. Wagner, S. Dehnen, Eur. J. Inorg. Chem. 2015, 2015, 5329.

[17] T. Yamase, H. Ishikawa, H. Abe, K. Fukaya, H. Nojiri, H. Takeuchi, Inorg Chem. 2012, 51, 4606

[18] a) S. K. Langley, D. P. Wielechowski, V. Vieru, N. F. Chilton, B. Moubaraki, B. F. Abrahams, L. F. Chibotaru, K. S. Murray, Angew. Chem. Int. Ed. 2013, 52, 12014; Angew. Chem. 2013, 125, 12236; b) S. K. Langley, D. P. Wielechowski, V. Vieru, N. F. Chilton, B. Moubaraki, L. F. Chibotaru, K. S. Murray, Chem. Sci. 2014, 5, 3246. 


\section{Entry for the Table of Contents}

\section{COMMUNICATION}

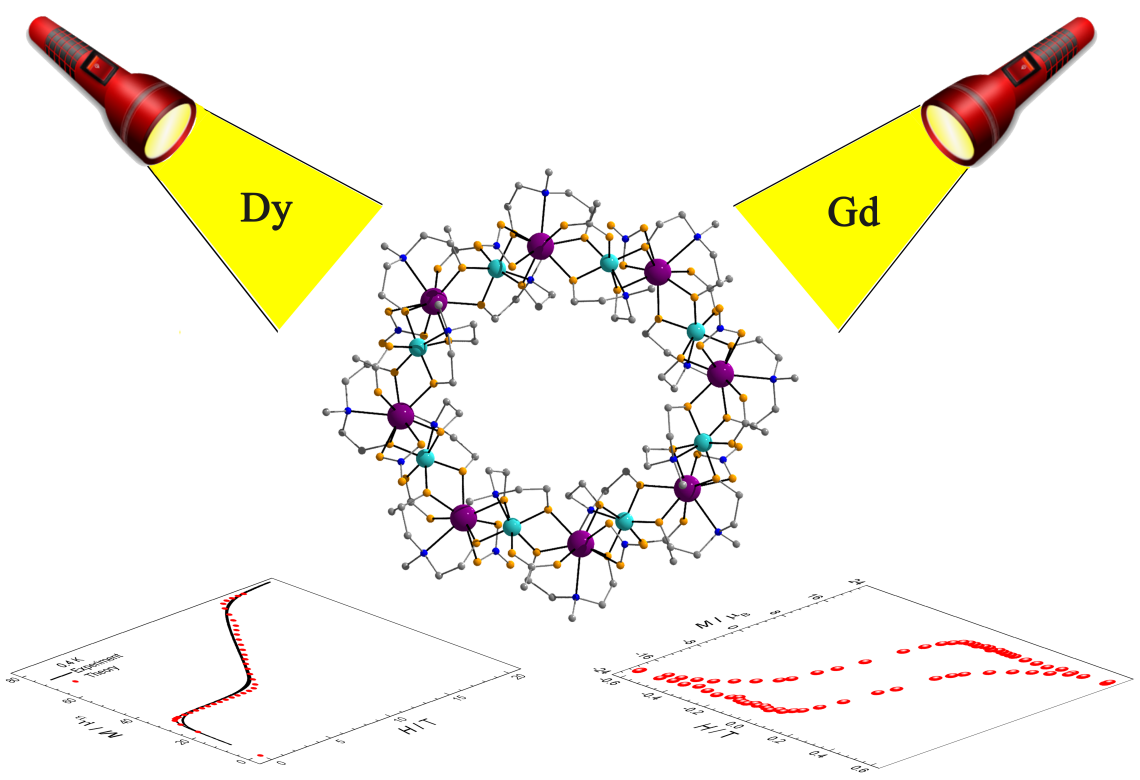

L. Qin, J. Singleton, W.-P. Chen, H.Nojiri, L. Engelhardt, * R. E. P. Winpenny ${ }^{*}$ and Y.-Z. Zheng*

Page No. - Page No.

Quantum Monte Carlo Simulations and High-Field Magnetization Studies of Antiferromagnetic Interactions in a Giant Hetero-Spin Ring

The exchange-coupling constants of the largest $\mathrm{Cr}(\mathrm{III})-\mathrm{Ln}(\mathrm{III})$ wheel was exactly predicted and experimentally confirmed using pulsed high field magnetization technique, which leads to a large ground spin state $\left(S_{T}=16\right)$ for the $G d$ analogue and a tunnelling-free singlemolecule magnet behavior for the Dy analogue. 